\title{
Three attempts of earthquake prediction with satellite cloud images
}

\author{
G. Guangmeng and Y. Jie \\ Remote Sensing Center, Nanyang Normal University, China \\ Correspondence to: G. Guangmeng (guogm@igsnrr.ac.cn)
}

Received: 4 June 2012 - Revised: 21 December 2012 - Accepted: 22 December 2012 - Published: 22 January 2013

\begin{abstract}
Thermal anomalies detected from satellite data are widely reported. Nearly all the anomalies are reported after the quake. Here we report three earthquake predictions in Italy and Iran according to satellite cloud anomalies. These cloud anomalies usually show a linear pattern, stay there for hours and do not move with winds. According to these anomalies, we can give a rough estimation about impending earthquake activities. All the estimated dates and magnitudes are in good agreement with the earthquake facts, and the only unsatisfactory point is that the distance error is $100-300 \mathrm{~km}$. Because the cloud anomaly is long, we can not reduce the distance error further. A possible way is to combine geophysical data and satellite data together to estimate the epicenter and this will increase the prediction accuracy.
\end{abstract}

\section{Introduction}

In 1997 Russian scientist Morozova found some abnormal linear clouds above an active fault (Morozova, 1997). This is the first report that clouds may have some relation with geological activity. In 1999 Shou considered that some strange clouds were related with earthquake. He predicted some earthquakes according to the cloud precursors and reported them to the USGS and had some success (Shou, 1999). In 2008 Guo and Wang (2008) studied a cloud anomaly before the $M=6.8$ Bam earthquake of 26 December 2003 (Guo and Wang, 2008). In that paper some strange clouds were observed before this and other Iran earthquakes. Wu et al. (2009) reported two abnormal linear clouds before $\mathrm{M}=8.0$ Wenchuan Earthquake of China (Wu et al., 2009). These clouds showed an abnormal pattern, they stayed over the main geology fault for hours, and did not move with the wind. Until now none meteorological theory can explain this phenomenon. Several days or months later after the clouds appearance, the quakes happened close the clouds and the faults.

On one hand, earthquake short time prediction is considered extremely difficult and controversial; on the other hand, many scientists try to study the anomalies before earthquake, such as the ionosphere TEC anomaly before the earthquakes in China, Japan, Indonesia and Haiti (Liu et al., 2004), thermal anomalies before the earthquakes in India, Iran, China and Italy (Qiang et al., 1991, 1992; Tronin, 2000; Saraf and Choudhury, 2005; Choudhury et al., 2006; Ouzounov et al., $2006,2007)$ and the radon anomaly before the earthquake in Japan (Yumi et al., 2006). Nearly all the anomalies are reported after the quake, not before the quake, and this leads to questions why people can not predict earthquakes according to these anomalies. Here we report 3 earthquake prediction examples according to satellite cloud image. Such kinds of work are seldom reported. A possible reason may be that scientists are limited in different disciplines. For example meteorologists who are familiar with geostationary satellite image do not study earthquake activity, and geologists who are familiar with earthquake activity do not study meteorology activity. This awkward situation limits the progress in earthquake prediction research.

\section{Data and method}

Here geostationary satellite imagery with $1 \mathrm{~h}$ temporal resolution is used. Its resolution is enough to monitor the cloud continuous movement. Polar orbit satellite data such as AVHRR or MODIS can not do this, because their temporal resolution is about $12 \mathrm{~h}$, and sometimes the cloud anomaly existed less than $10 \mathrm{~h}$. So they will not detect such anomaly. In current preliminary stage there is no formula or equation can be used to quantify such cloud anomaly. Our new developed method is combining the cloud image series into a computer animation, and then running this animation. In 


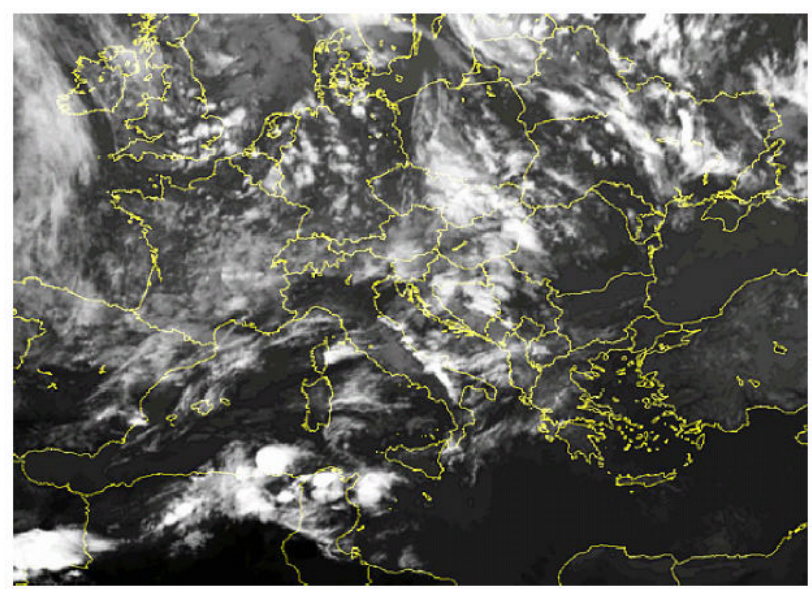

April 22 18:00UTC

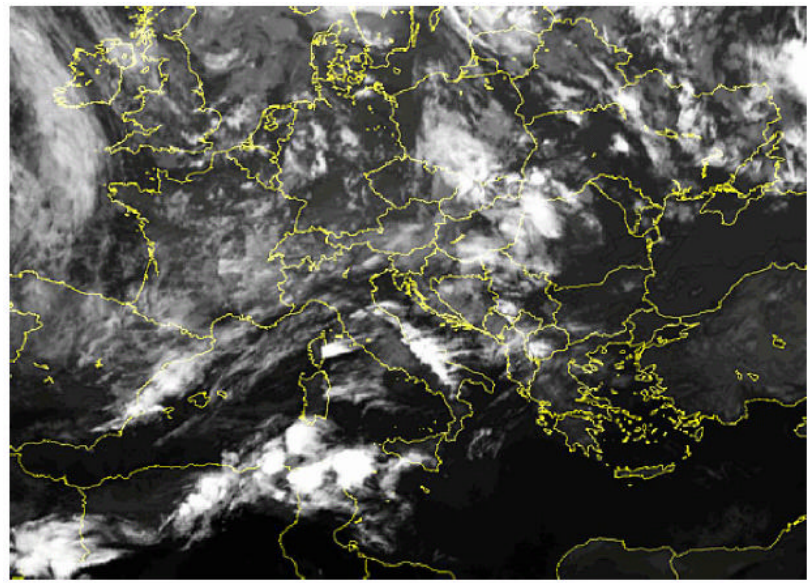

April 22 20:00UTC

Fig. 1. Geostationary satellite image of Europe from 22 April 18:00 UTC to 23 April 02:00 UTC.

the normal situation, the cloud will move fluently in the sky, except when the clouds are affected by an active fault, the clouds shape will change and pause sometime, while the normal cloud is still moving. According to this change we can identify the abnormal clouds.

\section{The Italy earthquake prediction}

On 22 April 2012, a linear cloud appeared over eastern Italy. Figure 1 shows the cloud movement from 22 April, 18:00 UTC to 23 April, 02:00 UTC. The straight linear cloud appeared on April 22, 18:00 UTC, it spread from central Italy to south Italy, about $200 \mathrm{~km}$ long and it nearly coincided with the main thrust fault of Italy. At 20:00 UTC, the cloud became wider, while its left edge was still there and did not move. On 23 April, 00:00 UTC, the left edge was very clear and it looked like cut with a knife. It stayed in-place for about $8 \mathrm{~h}$, and did not move with winds. In the whole of Europe, all

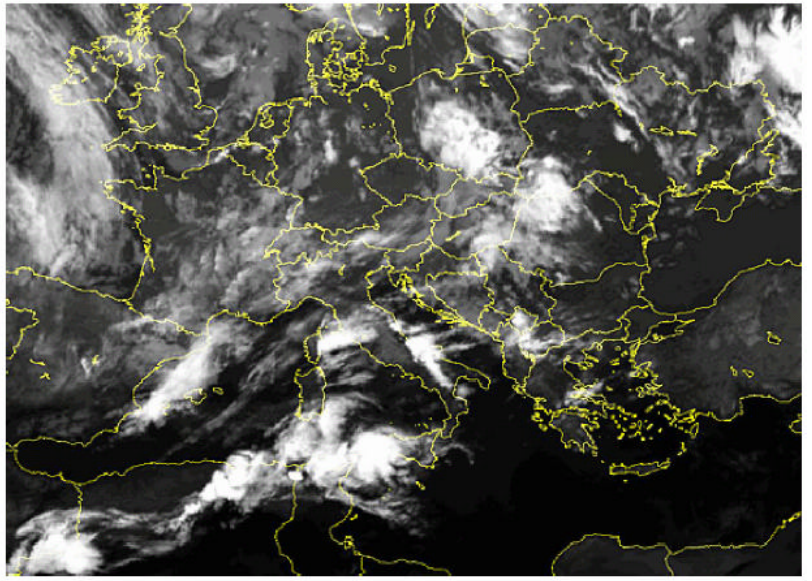

April 22 22:00UTC

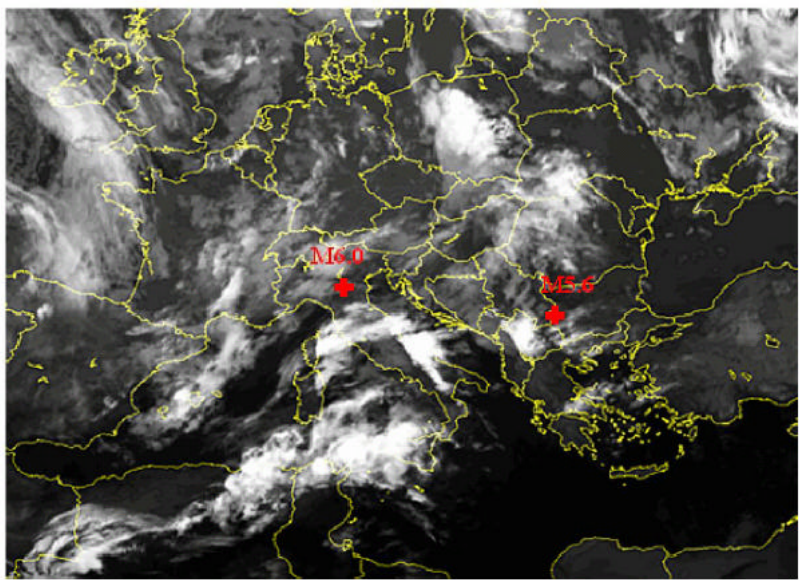

April 23 00:00UTC

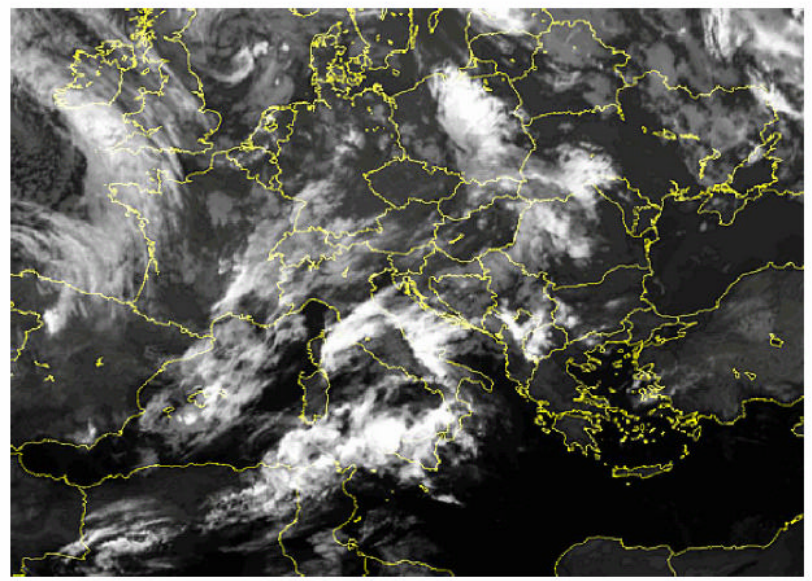

April 23 02:00UTC

Fig. 1. Continued.

the clouds were moving except this linear cloud over Italy. A similar but small cloud also existed over north of Greece.

We know that in normal situations clouds should move with winds continuously, while in this image, the cloud 
stayed there and did not move with winds for hours. It looks like some unknown force was dragging and hampering this cloud to move. In Freund's P-hole theory and rock experiments, he suggests that when the rocks are under high stress, it will ionize the air and produce positive airborne ions. The continuous supply of positive ions may be the reason why "stationary clouds" form over fault regions (Freund et al., 2009). We consider that this means the underground geological activity is becoming active, and according to this anomaly we make this prediction: "According to the satellite data, there will be $M=5.5-6.0$ quake in Italy. If $M=5.5$, it is about in 10 days, If $M=6.0$, it is in 30 days. I am trying to reduce the location error, but my data is limited." This prediction was sent to Angelo DeSantis, researcher of Italy's National Institute for Geophysics and Vulcanology and Hattori Katsumi, professor of Japan Chiba University on 23 April. At the same time, a small cloud anomaly appeared above Corsica, the island to the west. Its width was small compared to the cloud over Italy, so in this large area there were two cloud anomalies. Because the area is large, it is difficult to estimate the epicenter accurately, that is why we just gave a predicted location "Italy". Also because the area was large, so it meant a strong quake. That is why we predicted $\mathrm{M}=6.0$.

The $\mathrm{M}=5.5-6.0$ magnitude estimation is based on the large area of the cloud anomaly, because it appears in Italy and north Greece, and it is about $200 \mathrm{~km}$ long in Italy. The date is based on our experience in Iran and China. The only disadvantage is that the epicenter is difficult to estimate due to the large area of cloud anomaly. So we tried to get some field measurement data such as radon or ground water data from Italy and tried to reduce the epicenter location error. But we did not obtain usable data. On 20 May 2012 a $\mathrm{M}=6.0$ quake occurred at $44.800^{\circ} \mathrm{N}, 11.192^{\circ} \mathrm{E}$, and a $\mathrm{M}=5.8$ quake occurred at $44.814^{\circ} \mathrm{N}, 11.079^{\circ} \mathrm{E}$ on 29 May 2012 (reported by USGS). The $\mathrm{M}=6.0$ quake was the largest in Italy since the $\mathrm{M}=6.3 \mathrm{~L}^{\prime}$ Aquila quake in 2009. An interesting point is that a $\mathrm{M}=5.6$ quake occurred in Bulgaria at $42.686^{\circ} \mathrm{N}$, $23.009^{\circ} \mathrm{E}$ on 22 May 2012 , very close to the small cloud anomaly in North Greece (see Fig. 2). From 1970 to the present time, there were only 9 quakes larger than $M=5.0$ in region of Bulgaria. So it is unlikely that this $M=5.6$ quake was a mere coincidence with the cloud anomaly.

\section{The Iran earthquake prediction}

On 19 February 2012, a cloud appeared over a major fault in Iran. Figure 2 shows the image at 06:00 UTC on 20 February. We can see that in the left part of the fault, there are thin clouds, while in the right part, as the cloud passed the main fault, thick clouds appeared suddenly. The cloud edge was straight and stationary for about 1 day, while clouds in other areas were moving continuously. So according to this anomaly, we make a prediction that there will be a medium to strong earthquake in south Iran, with the possible magni-

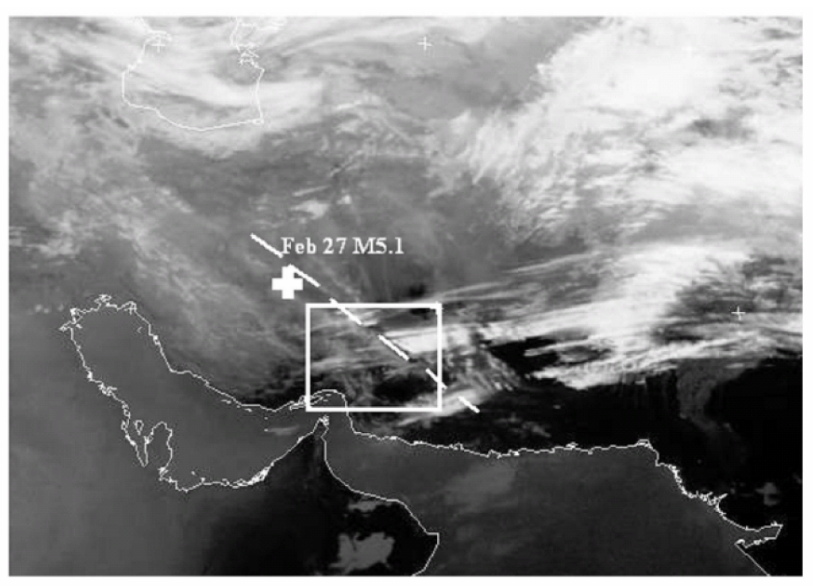

Fig. 2. Cloud image at 06:00 UTC on 20 February 2012. The dashed line is a major fault of Iran, and the square was our predicted future epicenter area.

tude $M=5.8-6.3$. Because the stationary cloud edge was so long, about $300 \mathrm{~km}$, it was difficult to predict the future epicenter location, possibly in the region $28^{\circ}-30^{\circ} \mathrm{N}, 58^{\circ}-60^{\circ} \mathrm{E}$. The earthquake time was also difficult to predict, because we have no information about the local geology activities, such as underground fluids, ground electric or local gravity. So we could only give a rough estimate, between 10 days to 30 days, and the possible date is in 10 days. We sent this prediction to the editor of International Journal of Remote Sensing and the earthquake administration of Nanyang city on 20 February. Seven days later, on 27 February 2012, a $\mathrm{M}=5.1$ earthquake occurred at $31.46^{\circ} \mathrm{N}, 56.76^{\circ} \mathrm{E}$ in south Iran (reported by USGS). So the location error of our prediction is $1.46^{\circ} \mathrm{N}$, $1.24^{\circ} \mathrm{E}$, and the magnitude error is 0.7 . Considering the current science technology, the absence of field data, and the big area of cloud anomaly, it is difficult to reduce this location error further. So we think this prediction can be counted as successful.

Table 1 lists the earthquake times in 2001-2011 within $28^{\circ}-32^{\circ} \mathrm{N}, 56^{\circ}-60^{\circ} \mathrm{E}$ of south Iran. All these earthquakes have magnitudes larger than or equal to $M=5.0$. The record shows that average frequency of earthquakes $(M \geq 5.0)$ in south Iran is 250 days. While in our prediction the quake comes only 7 days after we made the prediction, the metric for a successful possibility is $7 / 250=2.8 \%$ for a prediction according to the 250 days frequency. This means that our prediction is most likely not a coincidence. Will the earthquake activity of Iran be quiet for some weeks after the $\mathrm{M}=5.1$ earthquake of 27 February? According to our study, the answer is no. We found another cloud anomaly on 1 March (see Fig. 3). Its pattern was similar as Fig. 2, so according to this cloud anomaly we made a second prediction: "According to the satellite data, fault activity of Iran is still in a high stress. So we predict, there will be a $\mathrm{M}=5.0-6.0$ quake in Iran from 2 March to 17 March. 7-8 March is a 
Table 1. Number of earthquakes ( $\geq \geq 5$.0) from 2001-2011 in southern Iran.

\begin{tabular}{lrrrrrrrrrrrrr}
\hline Year & 2001 & 2002 & 2003 & 2004 & 2005 & 2006 & 2007 & 2008 & 2009 & 2010 & 2011 & total & frequency \\
\hline Quake times & 1 & 0 & 4 & 1 & 2 & 1 & 1 & 0 & 0 & 2 & 4 & 16 & 250 days \\
\hline
\end{tabular}

Table 2. Lists of four earthquake dates and magnitudes.

\begin{tabular}{lllll}
\hline $\begin{array}{l}\text { Date of cloud } \\
\text { anomaly }\end{array}$ & $\begin{array}{l}\text { Date of } \\
\text { earthquake }\end{array}$ & $\begin{array}{l}\text { Time } \\
\text { duration } \\
\text { (day) }\end{array}$ & Magnitude & Location \\
\hline 23 April 2012 & 20 May 2012 & 27 & $\mathrm{M}=6.0$ & Italy \\
23 April 2012 & 22 May 2012 & 29 & $\mathrm{M}=5.6$ & Bulgaria \\
19 February 2012 & 27 February 2012 & 8 & $\mathrm{M}=5.1$ & Iran \\
1 March 2012 & 8 March 2012 & 7 & $\mathrm{M}=5.1$ & Iran \\
\hline
\end{tabular}

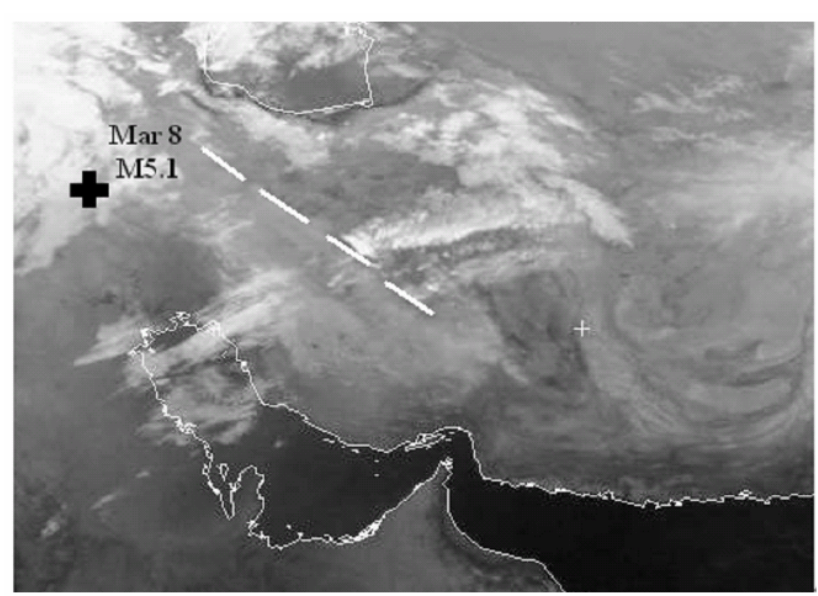

Fig. 3. Cloud image at 00:00 UTC on 1 March 2012.

likely date." This prediction was sent to the editor of International Journal of Remote Sensing and the earthquake administration of Nanyang city on 2 March. The fact is a $\mathrm{M}=5.1$ quake occurred at $32.91^{\circ} \mathrm{N}, 46.98^{\circ} \mathrm{E}$ on 8 March in North Iran (reported by USGS). In this prediction our estimate of impending earthquake activity and the earthquake time were accurate. Because their distance is larger than $500 \mathrm{~km}$, and their magnitude are both $M=5.1$, so they are probably two isolated quakes. Statistically according to the 250 days frequency, the chance of making a successful prediction is $2 / 250=0.8 \%$. The chance of making 2 consecutive predictions such as ours, the probability will be $7 / 250 \cdot 2 / 250=$ $0.0224 \%$. So this shows that it is nearly impossible to make 2 consecutive successful predictions according the earthquake history data. While with the help of satellite data, we make two partly successful predictions.

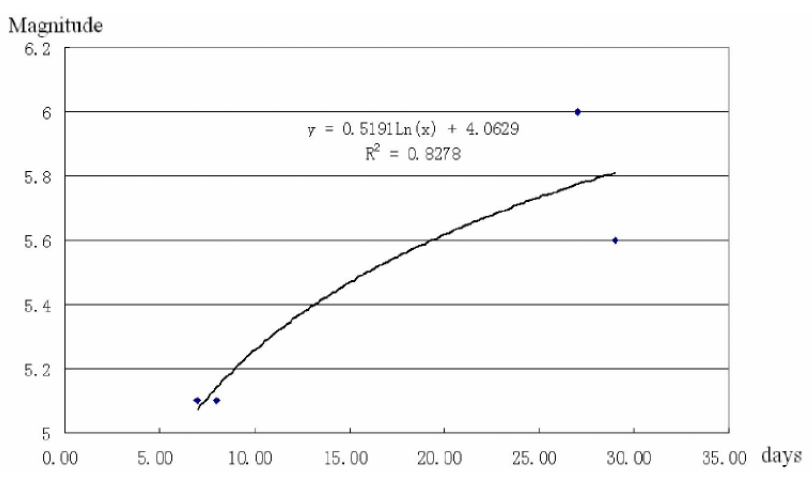

Fig. 4. Scatter map of four earthquake's preparation time and magnitude.

\section{Discussions}

Of course earthquake prediction is a very difficult task, and many even think it is impossible (Robert et al., 1997). Here we presented three earthquake prediction attempts where we were able to register some success. We made three predictions, and all three became true. The dates and magnitudes were acceptable, and the distance error was about 100 $300 \mathrm{~km}$. From Table 2 and Fig. 4, we can see that bigger earthquakes seem to need more time to prepare, and this is reasonable with current knowledge, although only 4 quakes are listed due to earthquake prediction being extremely difficult.

Unlike the gravity and geomagnetic measurement which need millions of dollars to build a station and transfer network, the method presented here is very inexpensive because anyone can download satellite data from the internet and analyze them. Note that our prediction is only based on satellite cloud images; we use no field survey, no in situ measurement and no other geophysical data. Cloud anomaly observed in some region indicates that there is stress build-up in this area, and this means there is a high probability of a major seismic 
event. But we must note that not every cloud anomaly corresponds to an earthquake. To reduce the false alarm, we can use some other geophysical data such as ground water, ground electric, gravity, and combine them together with satellite data. For example, ground electrical measurements will enable the estimation of the epicenter and magnitude of the impending earthquake (Varotsos et al., 1986) along with the determination of its occurrence time (Sarlis et al., 2008). Qin et al. (2012) analyze air temperature data before the same Italy $\mathrm{M}=6.0$ quake and finds that from 20:00 to 23:00 UTC on 12 May 2012, an obvious high temperature area appeared above the epicenter region, then gradually weakened and narrowed onto the epicenter. These independent verifications can increase the reliability of earthquake prediction. So we think that this method has great potential in earthquake prediction.

\section{Supplementary material related to this article is available online at: http://www.nat-hazards-earth-syst-sci.net/13/91/2013/ nhess-13-91-2013-supplement.zip.}

Acknowledgements. This work was supported by NSFC project (41071280). The satellite data were provided by Dundee Satellite Receiving Station and www.sat24.com. Many thanks for the reviewer's great assistance in evaluating this paper. Their help are greatly appreciated.

Edited by: M. E. Contadakis

Reviewed by: L. X. Wu and F. T. Freund

\section{References}

Choudhury, S., Dasgupta, S., Saraf, A. K., and Panda, S. K.: Remote sensing observations of pre-earthquake thermal anomalies in Iran, Int. J. Remote Sens., 27, 4381-4396, 2006.

Freund, F. T., Kulahci, I., Cyr, G., Ling, J., Winnick, M., TregloanReed, J., and Freund, M. M.: Air ionization at rock surfaces and pre-earthquake signals, J. Atmos. Sol.-Terrest. Phys., 71, 18241834, 2009.

Guo, G. M. and Wang, B.: Cloud anomaly before Iran earthquake, Int. J. Remote Sens., 2, 1921-1928, 2008.
Liu, J. Y., Chuo, Y. J., Shan, S. J., Tsai, Y. B., Chen, Y. I., Pulinets, S. A., and Yu, S. B.: Pre-earthquake ionospheric anomalies registered by continuous GPS TEC measurements, Ann. Geophys., 22, 1585-1593, doi:10.5194/angeo-22-1585-2004, 2004.

Morozova, L. I.: Dynamics of cloudy anomalies above fracture regions during natural and anthropogenically caused seismic activities, Fizika Zemli, 9, 94-96, 1997.

Ouzounov, D., Bryant, N., Logan, T., Pulinets, S., and Taylor, P.: Satellite thermal IR phenomena associated with some of the major earthquakes in 1999-2004, Phys. Chem. Earth, 31, 154-163, 2006.

Ouzounov, D., Liu, D., Kang, C.,Cervone, G., Kafatos, M., and Taylor, P.: Outgoing long wave radiation variability from IR satellite data prior to major earthquakes, Tectonophysics, 431, 211-220, 2007.

Qiang, Z. J., Xu, X. D., and Dian, C. G.: Thermal infrared anomaly precursor of impending earthquakes, Chinese Sci. Bull., 36, 319323, 1991.

Qiang, Z. J., Dian, C. G., Wang, X. J., and Hu, S. Y.: Satellite thermal infrared anomalous temperature increase and impending earthquakes precursor, Chinese Sci. Bull., 37, 1642-1646, 1992.

Qin, K., Wu, L. X., De Santis, A., and Cianchini, G.: Preliminary analysis of surface temperature anomalies that preceded the two major Emilia 2012 earthquakes (Italy), Ann. Geophys., 55, 823828, 2012, http://www.ann-geophys.net/55/823/2012/.

Robert, J. G., Jackson, D. D., Kagan, Y. Y., and Mulargia, F.: Earthquakes Cannot Be Predicted, Science, 275, 1616-1617, 1997.

Saraf, A. K. and Choudhury, S.: Thermal remote sensing technique in the study of pre-earthquake thermal anomalies, J. Ind. Geophys. Union, 9, 197-207, 2005.

Shou, Z. H., Earthquake Clouds, a reliable precursor, Science \& Utopya, 64, 53-57, 1999.

Sarlis, N. V., Skordas, E. S., Lazaridou, M. S., and Varotsos, P. A.: Investigation of seismicity after the initiation of a Seismic Electric Signal activity until the main shock, Proc. Jpn Acad. Ser. B. Phys. Biol. Sci., 84, 331-343, 2008.

Tronin, A. A.: Thermal IR satellite sensor data application for earthquake research in China, Int. J. Remote Sens., 21, 3169-3177, 2000.

Varotsos, P., Alexopoulos, K., Nomicos, K., and Lazaridou, M.: Earthquake prediction and electric signals, Nature, 322, 120, doi:10.1038/322120a0, 1986.

Wu, L. X., Li, J. P., and Liu, S. J.: Space Observed Two Abnormal Linear Clouds before Wenchuan Earthquake. 3rd IASME/WSEAS Int. Conf. Geol. Seismol., Cambridge, UK, 138-143, 2009.

Yasuoka, Y., Igarashi, G., Ishikawa, T., Tokonami, S., and Shinogi, M.: Evidence of precursor phenomena in the Kobe earthquake obtained from atmospheric radon concentration, Appl. Geochem., 21, 1064-1072, 2006. 